\title{
Atendimento odontológico de urgência em meio à pandemia do COVID- 19: relato de caso clínico
}

\author{
Emergency dental care during COVID-19 pandemic: clinical case report
}

Atención dental de emergencia durante la pandemia de COVID-19: reporte de caso clínico

Thaine Oliveira Lima ${ }^{1 *}$, Aurélio de Oliveira Rocha ${ }^{1}$, Lucas Menezes dos Anjos², Jardel Gomes da Silva ${ }^{1}$, David Wendell Soares Santos ${ }^{1}$, Max Dória Costa ${ }^{1}$.

\section{RESUMO}

Objetivo: Relatar um caso clínico de urgência odontológica no período da pandemia por COVID-19. Detalhamento do caso: Paciente do gênero feminino, 55 anos, procurou atendimento em Clínica Odontológica queixando-se: "meu dente da frente caiu". Antes do atendimento, foi realizado questionário referente à possível contaminação pelo novo coronavirus via telefone, e abordagem a fim de concluir se o caso da paciente se enquadrava como atendimento de urgência. Visto que a paciente realmente necessitava do atendimento, foi feito o agendamento. Clinicamente a paciente apresentava coroa fraturada da unidade 11 , onde foi realizada a instalação de um pino de fibra de vidro e cimentação de coroa provisória em única sessão. O cirurgião-dentista responsável pelo atendimento seguiu todas as orientações de precauções recomendadas pelos Orgãos de Saúde. Considerações finais: Neste momento cabe o discernimento para execução de procedimentos odontológicos de maneria segura, visto o potencial de infecção na saliva e formação exuberante de aerossóis provenientes da realização dos procedimentos odontológicos.

Palavras-chave: COVID-19, Prótese parcial fixa, Tratamento odontológico.

\begin{abstract}
Objective: To report a clinical case of dental urgency during the pandemic period due to COVID-19. Details of the case: A 55-year-old female patient sought care at a Dental Clinic complaining: "my front tooth fell". Before the appointment, a questionnaire was carried out regarding the possible contamination by the new coronavirus via telephone, and embroidering in order to conclude whether the patient's case was classified as emergency care. Since the patient really needed care, an appointment was made. Clinically, the patient had a fractured crown from unit 11, where a fiberglass pin and provisional crown cementation were performed in a single session. The dental surgeon responsible for the care followed all the precautionary guidelines recommended by the Health Organs. Final considerations: At this moment it is up to the discernment to perform dental procedures safely, given the potential for infection in the saliva and the exuberant formation of aerosols from the dental procedures.
\end{abstract}

Keywords: COVID-19, Fixed partial denture, Dental treatment.

\section{RESUMEN}

Objetivo: Informar un caso clínico de urgencia dental durante el período pandémico por COVID-19. Detalles del caso: Una paciente de 55 años buscó atención en una Clínica Dental quejándose: "se me cayó el diente frontal". Previo a la cita, se realizó un cuestionario sobre la posible contaminación por el nuevo coronavirus vía telefónica, y abordados con el fin de concluir si el caso del paciente estaba catalogado como urgente.

1 Universidade Tiradentes (UNIT), Aracaju - SE. *E-mail: thaineol95@gmail.com

2 Universidade Federal de Sergipe (UFS), Aracaju - SE. 
Dado que el paciente realmente necesitaba atención, se concertó una cita. Clínicamente, el paciente tenía una corona fracturada de la unidad 11, donde se realizó un pin de fibra de vidrio y cementación de la corona provisional en una sola sesión. El cirujano dentista responsable de los cuidados siguió todas las pautas de precaución recomendadas por los Órganos de Salud. Consideraciones finales: En este momento corresponde al discernimiento realizar los procedimientos dentales de manera segura, dado el potencial de infección en la saliva y la exuberante formación de aerosoles de los procedimientos dentales.

Palabras clave: COVID-19, Prótesis parcial fija, Tratamiento dental.

\section{INTRODUÇÃO}

A pandemia causada por um novo coronavírus começou em Wuhan, na China, em dezembro de 2019, e se tornou um grande problema de saúde pública desafiador não apenas para a China, mas também para outros países do mundo (PHELAN AL, et al., 2020). Em 30 de janeiro de 2020, a Organização Mundial da Saúde (OMS) anunciou que esse surto constituíra uma emergência de saúde pública de interesse internacional (MAHASE E, 2020).

Em 11 de fevereiro, a doença respiratória decorrente da infecção pelo novo coronavirus chamada de Sindrome Respiratória Aguda Grave do Corona Vírus 2 (SARS-CoV-2) foi denominada COVID-19, onde 'CO' significa corona, 'VI' para vírus e 'D' para doença (DE CAMPOS TUÑAS IT, et al., 2020; LU CW, et al., 2020; MAHASE E, 2020). O curso clínico da doença é heterogêneo, sendo que uma parcela dos pacientes não apresenta sintomas, enquanto outra parcela evolui com quadro clínico classificados de leves/moderados ou severos.

Dentre os principais sinais e sintomas destacam-se: febre, tosse seca, apatia, mialgia, perda parcial ou total do olfato (hiposmia/anosmia) e alteração ou diminuição ou perda total do paladar (disgeusia/hipogeusia/ageusia), insuficiência renal e doença respiratória aguda com necessidade de ventilação mecânica invasiva (BAI Y, et al., 2020; GIACOMELLI A, et al., 2020, ANJOS LM, et al., 2020).

Entre os pacientes submetidos à tomografia computadorizada (TC) do tórax, a maioria apresentou pneumonia bilateral, com opacidade em vidro fosco e sombras irregulares bilaterais sendo os padrões mais comuns (GUAN WJ, et al., 2020; WANG D, et al., 2020).

Considerando que o SARS-CoV-2 foi recentemente identificado na saliva de pacientes infectados, o surto da COVID-19 é um lembrete de que os Cirurgiões-Dentistas devam se preocupar na disseminação de doenças infecciosas respiratórias (PENG X, et al., 2020; VAN DOREMALEN N, et al., 2020).

No entanto, em decorrência das características únicas dos procedimentos odontológicos onde um grande número de gotículas e aerossóis pode ser gerado, o risco de infecção cruzada é alto entre os dentistas, auxiliares e pacientes, devendo os procedimentos de geração de aerossóis ser minimizados o máximo possível nesse periodo (MENG L, et al., 2020).

As medidas padrão de proteção no trabalho clínico diário não são eficazes o suficiente para impedir a disseminação do COVID-19, especialmente quando os pacientes estão no período de incubação, não sabem que estão infectados ou optam por ocultar a infecção (MENG L, et al., 2020).

Durante o surto de COVID-19, as clínicas odontológicas são recomendadas a estabelecer triagens prévias ao telefone, questionando o paciente sobre o estado de saúde geral e o histórico de contatos ou viagens recentes (OMS, 2020).

Presenciamente aferir e registrar a temperatura da equipe e dos pacientes como um procedimento de rotina. Constatados sintomas de infecç̧ão respiratória, devem ser registrados e os pacientes encaminhados para atedimento médico especilizado. e o paciente esteve em regiões epidêmicas nos últimos 14 dias, sugerese quarentena por 14 dias, pois, acredita-se que o tempo de incubação do COVID-19 se estenda neste perídodo, com um tempo médio de 4-5 dias a partir da exposição para o aparecimento dos sintomas (PENG $X$, et al., 2020). 
A higiene das mãos tem sido considerada a medida mais eficaz para reduzir o risco de transmitir microorganismos (LARSON EL, et al., 2000). É importante limpar as mãos com água e sabão ou higienizar com alcool $70 \%$ antes e depois dos atendimentos.

Estudos anteriores mostraram que esfregar as mãos com alcool $70 \%$ ou alcool isopropilico $70 \%$ geralmente são eficazes contra vírus envelopados, incluindo SARS-CoV e MERS-CoV (MARTINS-FILHO PR, et al., 2020).

O SARS-CoV-2 pode persistir nas superfícies por algumas horas ou até vários dias, dependendo do tipo de superfície, da temperatura ou da umidade do ambiente (OMS, 2020). Isso reforça tanto a necessidade de uma boa higiene das mãos, como a importância de uma desinfecção completa de todas as superfícies da clínica odontológica.

Recomenda-se o uso de equipamentos de proteção individual, incluindo, propé, touca, mascaras N95 ou PFF-2, luvas, aventais impermeáveis descartáveis, óculos e protetores faciais, para proteger a pele e mucosa oral, nasal e ocular do aerosol, gotículas, sangue ou secreção potencialmente infectada (MENG L, et al., 2020). Considerando que o SARS-CoV-2 foi recentemente identificado na saliva de pacientes infectados, 0 surto da COVID-19 é um lembrete de que os Cirurgiões-Dentistas devem se preocupar na disseminação de doenças infecciosas respiratórias (PENG X, et al., 2020; VAN DOREMALEN N, et al., 2020).

Assim, o objetivo do presente trabalho é relatar um caso clínico de urgência odontológica no período da pandemia, informando sobre os cuidados que devem ser tomados pelo profissional para que se evite qualquer tipo de infecção por COVID-19.

\section{DETALHAMENTO DE CASO}

Paciente do gênero feminino, 55 anos, entrou em contato com a clínica odontológica procurando atendimento, com a seguinte queixa: "meu dente da frente caiu". Ainda por telefone, a paciente negou viagem, sintomas de infecção respiratória ou contato com pessoas sintomáticas nos últimos 14 dias antes da consulta. Devido os riscos de contaminação pelo novo coronavírus o atendimento foi realizado com horário marcado e tempo espaçado entre pacientes, para evitar aglomeração na sala de espera, além disso, sem a presença de acompanhante.

Ao chegar na clínica a paciente foi orientada a higienizar os solados dos pés em pano úmido com hipoclirito de sódio $1 \%$, calçar a capa de sapatos descartáveis (propé), higienizar as mãos com alcool gel $70 \%$, disponibilizados na recepção e aguardar na sala de espera utilizando máscara. Previamente ao atendimento foi realizado a desinfecção de todas as superfícies possíveis ao toque da paciente com álcool $70^{\circ}$, paramentação do cirurgião-dentista com avental descartável, gorro, máscara PFF2, protetor facial, sapato fechado e óculos de proteção, a fim de evitar qualquer tipo de contaminação cruzada.

De acordo com as recomendações atuais diante da pandemia, foi aferida a temperatura da paciente logo na chegada ao consultório, onde apresentava $36,7 \stackrel{\circ}{\circ} \mathrm{C}$. Na anamnese a mesma informou ter realizado tratamento reabilitador com pino intraradicular e coroa protética da unidade 11 há quatro anos, no entando, no dia anterior à consulta enquando praticava atividade física ao ar livre esta coroa caiu da boca não sendo possível encontra-la, demonstrando grande insatisfação referente ao quadro em que se apresentava, relatando dificuldade de alimentação, de limpeza adequada da região e atrapalhando o convívio social devido envolvimento estético, constatando ao exame clínico inicial da paciente sorrindo (Figura 1A).

Previamente ao exame clínico, foi orientado que a paciente realizasse o bochecho com Peróxido de Hidrogênio a 1\% durante 1 minuto. Na inspeção visual, foi observado além da ausência da coroa da unidade 11, presença do remanescente radicular saudável sem cárie nem fratura subgengival e tratamento endodôntico adequado, constatado radiograficamente, apesar do conduto exposto na cavidade bucal (Figuras 1B). 
Figura 1 - A) Exame clínico inicial do sorriso. B) Exame clínico intra oral inicial.
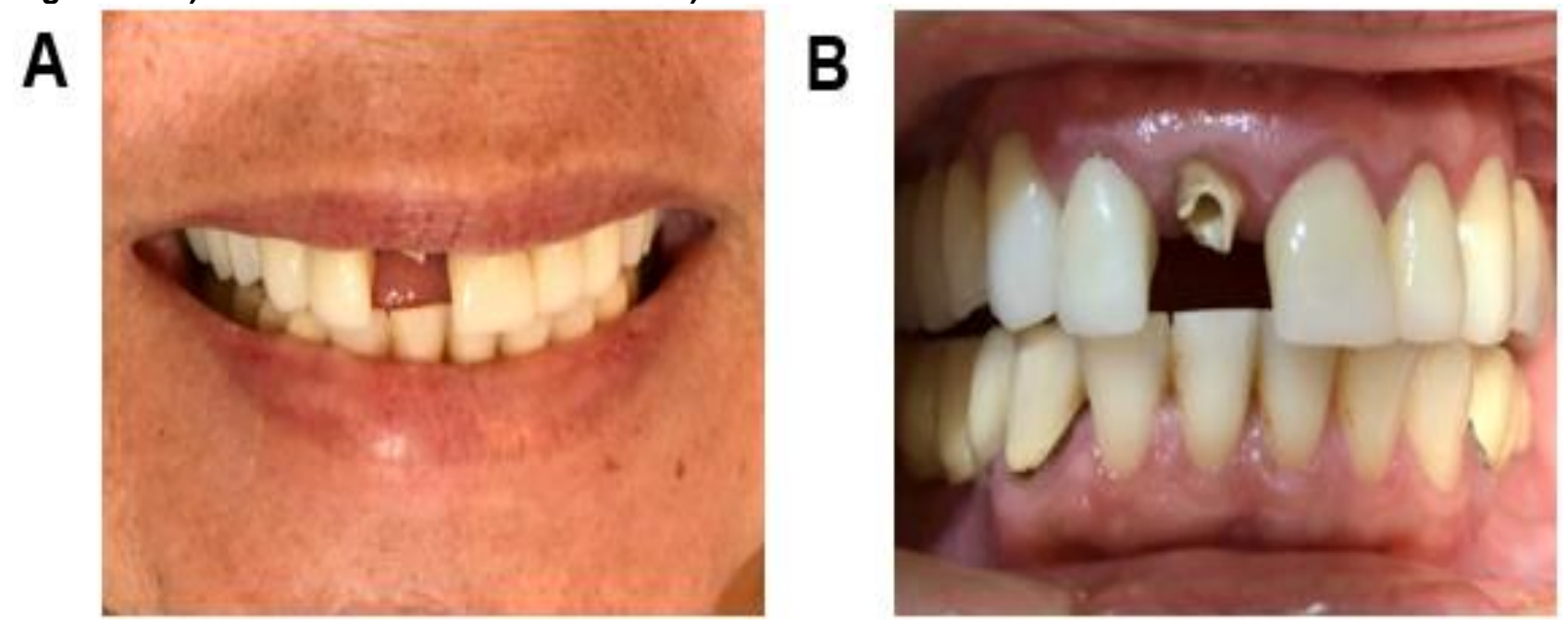

Fonte: LIMA TO, et al., 2020.

Foi proposto a reabilitação desta unidade por meio de cimentação de pino de fibra de vidro e instalação de prótese fixa do tipo coroa total unitária provisória em resina acrílica como tratamendo de urgência em virtude da pandemia, visando posterior realização de coroa definitiva em ceramica pura.

Diante da dificuldade em proceder o isolamento absoludo no remanescente dentário destruído, foi realizado o isolamento relativo da região com auxílio do abridor de boca (Morelli®), rolete de algodão estéril no fundo de vestibulo, matendo constantemente o sugador de alta pressão do tipo bomba a vacuo (Schuster $\AA^{\circledR}$ ), aspirando a cavidade oral do paciente, impedindo o acúmulo e consequentmente gotículas de saliva. Foi realizado a cimentação do pino de fibra (Ângelus ${ }^{\circledR}$ ) tamanho 1, e a confecção do núcleo de preenchimento com resina composta na cor $\mathrm{A} 1 \mathrm{Z250}\left(3 \mathrm{M}{ }^{\circledR}\right)$ fotoativada (VALO®) (Figura 2).

Figura 2 - Posicionamento do pino no conduto e núcleo de preencimento em resina composta após fotopolimerização.

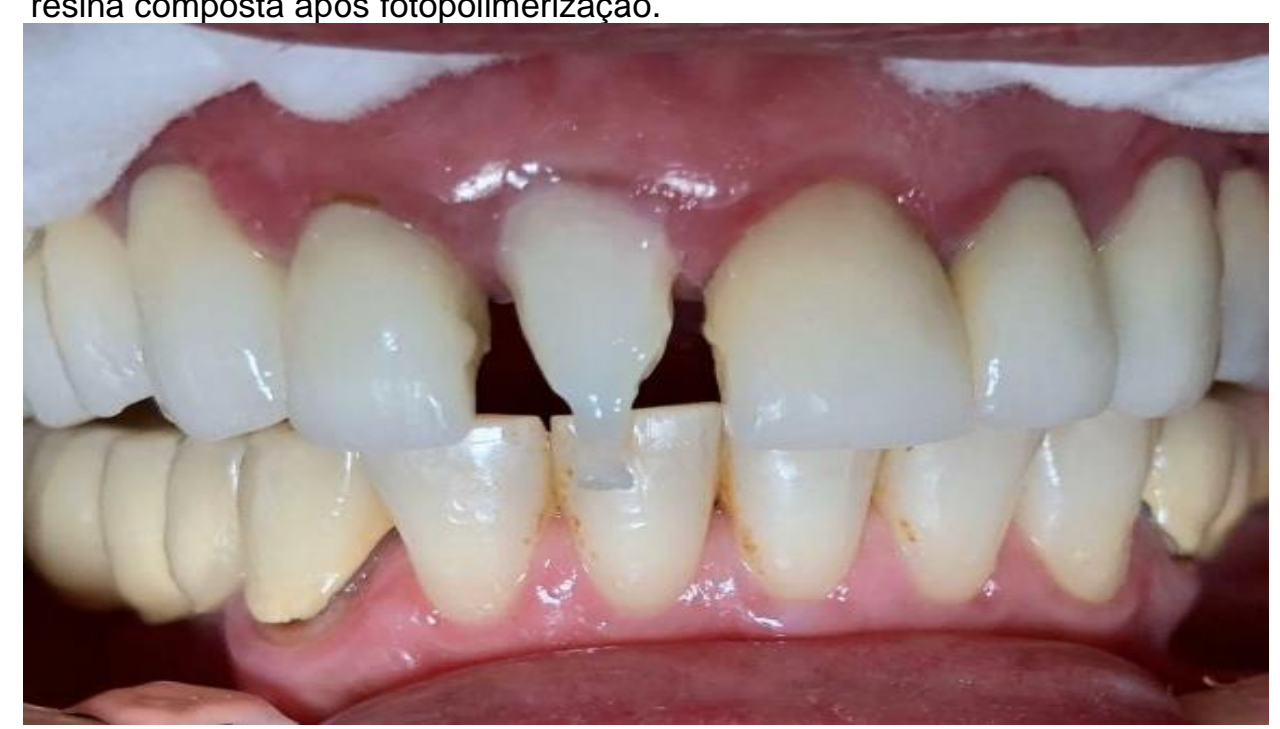

Fonte: LIMA TO, et al., 2020.

Para remoção do excesso do pino e realização do formato do preparo para coroa total, foi utilizada ponta diamantada cilíndrica de extremidade plana 3097 (KG SORENSEN®) nas paredes circundantes ao redor do núcleo de e ponta em formato de pêra ou chama 3118 (KG SORENSEN®) para confeccionar a concavidade palatine (Figura 3). Ambas em alta rotação $(K A V O \circledast)$ com pouca irrigação e aspiração constante com sugador de alta pressão para gerar o mínimo de aerosol. 
Figura 3 - preparo protético confeccionado.

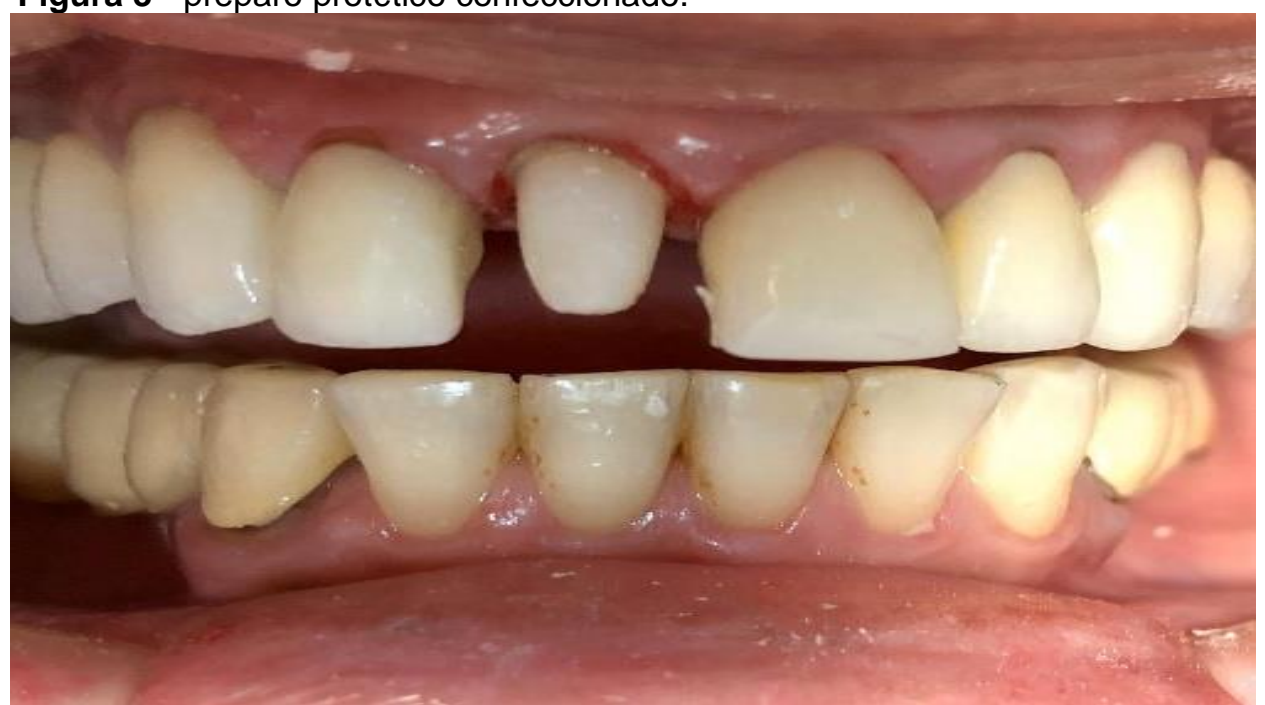

Fonte: LIMA TO, et al., 2020.

Em seguida, foi realizada confecção da coroa provisória através da técnica do dente de estoque. Foi avaliada a oclusão com papel carbono (ACCUFILM®) e delimitado o término cervical da coroa provisória com grafite 07 , para remoção dos excessos com brocas maxicut, seguido de acabamento e polimento com borrachas (AMERICANBURS $\left({ }^{\circledR}\right)$ para lisura e brilho. Por fim, foi realizada a cimentação com fosfato de zinco (SSWHITE®) (Figura 4).

Figura 4 - Cimentação da prótese fixa provisória finalizada.

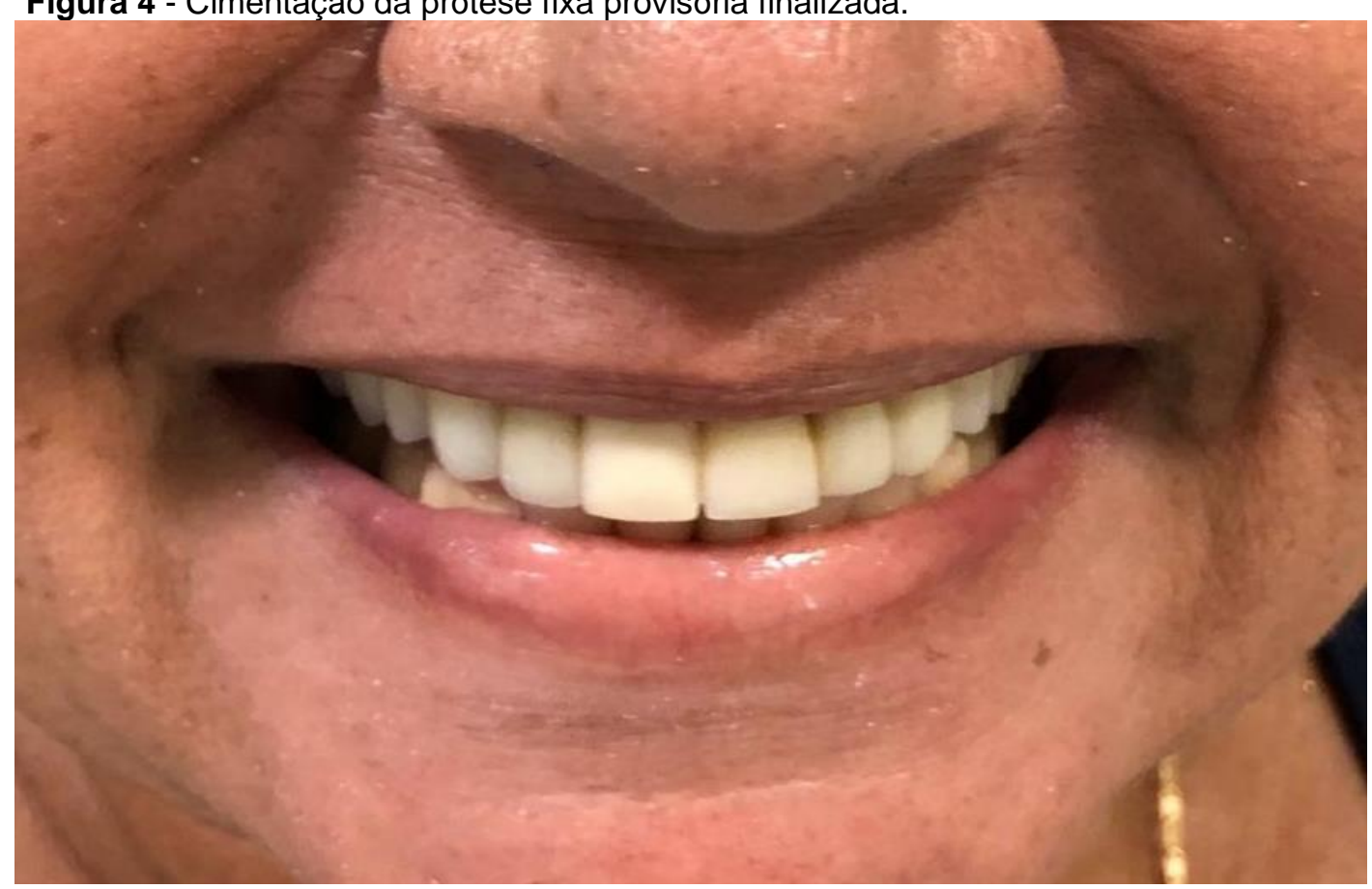

Fonte: Lima TO, et al., 2020.

\section{DISCUSSÃO}

Previamente à consulta ainda por telefone os profissionais de odontologia devem ser capazes de identificar um caso suspeito de COVID-19. Os pacientes devem responder a um conjunto de perguntas destinadas a investigar o risco de exposição ao SARS-CoV-2 (PENG X et al., 2020). A perda do paladar e de olfato são considerados sinais prodrômicos e também podem ser questionados (GIACOMELLI A, et al., 2020). 
Os pacientes podem visitar o consultório odontológico somente se todo o questionário for negativo; caso contrário a consulta deve ser adiada (IZZETTI R, et al., 2020). No caso relatado, foi realizado o contato prévio via telefone com a paciente, colhendo informações necessárias que pudessem garantir a possibilidade e segurança do atendimento.

Se um paciente responder afirmativo para qualquer uma das perguntas de triagem, e sua temperatura corporal for superior a $37,3^{\circ} \mathrm{C}$, o paciente deve ser imediatamente colocado em quarentena e os profissionais de odontologia devem se reportar ao departamento de controle de infecções do hospital ou ao departamento de saúde local (PENG X, et al., 2020; DE CAMPOS TUÑAS IT, et al., 2020; IZZETTI R, et al., 2020). Desta forma, no caso clinico relatado o paciente foi atendido por responder negativo para todas as perguntas de triagem e a temperatura corpórea estar abaixo de $37,3^{\circ} \mathrm{C}$. Devido à natureza do ambiente de trabalho, à contaminação cruzada é um desafio para a profissão odontológica, onde são gerados aerossóis e gotículas durante os procedimentos de rotina (IYER P, et al., 2020).

As precauções padrão não são suficientes para impedir a disseminação do coronavírus, especialmente durante a fase de incubação do COVID-19 (MENG L, et al, 2020). Desta forma, sabe-se que a realização de bochechos pelo paciente prévios ao tratamento, reduzem a quantidade de microrganismos dispersos nas superfícies e dispostas no ambiente.

Estudos relatam que o bochecho com Clorexidina a 0,12\%, usualmente utilizado em Odontologia, não é eficaz na prevenção da transmissão do Coronavírus. Como o vírus é susceptível à oxidação, o uso de Peróxido de Hidrogênio a $1 \%$ e Lodopovidona a $0,2 \%$ ao tratamento é recomendado (IZZETTI R, et al., 2020, DE CAMPOS TUÑAS IT, et al., 2020).

Outras opções seriam o bochecho com cloreto de cetilpiridínio de 0,05\% a 0,1\%, por 1 minuto antes do procedimento odontológico (IZZETTI R, et al., 2020). Porém, um estudo mais recente constatou que a carga viral na saliva diminuiu transitoriamente por 2 horas após o uso do enxaguatório bucal com clorexidina a $0,12 \%$, mas aumentou novamente de 2 a 4 horas após o uso, concluindo que o enxaguatório bucal com clorexidina foi eficaz na redução da carga viral SARS-CoV-2 na saliva por um período de curto prazo (YOON JG, et al., 2020).

No presente caso, a paciente fez uso no Peróxido de Hidrogênio a 1\% durante 1 minuto, por se tratar de um agente oxidante bastante eficaz na inibição do SARS-CoV-2, de acordo com a literatura (IZZETI R, et al., 2020). Com base em diretrizes e pesquisas relevantes, os dentistas além de adotar medidas estritas de proteção individual, deve evitar ou minimizar operações que possam produzir gotículas ou aerossóis (MENG L, et al., 2020). Peng $X$ et al. (2020) destacaram o risco relacionado à realização de procedimentos odontológicos, prncipalmente quando turbinas de alta rotação e dispositivos ultrassônicos com irrigação são empregados.

O uso do lençol de borracha para isolamento absoluto do campo operatório é altamente recomendado, pois minimiza a produção de aerossol contaminado por saliva e sangue, quando alta rotação ou ultrassom são empregados (DE CAMPOS TUÑAS IT, et al., 2020; MENG L et al. 2020; PENG $X$ et al. 2020). Nos casos em que o lençol de borracha não é utilizado para o procedimento odontológico, os enxaguatórios bucais são altamente recomendados (IZZETTI R, et al., 2020). No caso relatado, o remanecente dentário curto e frágil impossibilitou o uso do isolamento absoluto, e diante disso, o bochecho se fez indispensável.

Como a transmissão de gotículas no ar é considerada a principal via de disseminação do COVID19, principalmente em clínicas odontológicas e hospitais, equipamentos de proteção individual, incluindo, máscara, luva, gorro, avental descartáveis, além de óculos de proteção e protetores faciais, é altamente recomendado para todos os prestadores de cuidados de saúde durante o período pandêmico do COVID-19 (PENG X, et al., 2020; DE CAMPOS TUÑAS IT, et al., 2020; IZZETTI R, et al., 2020).

Óculos de grau não são considerados equipamentos de proteção individual, pois não possuem as proteções laterais (DE CAMPOS TUÑAS IT, et al., 2020). Recomenda-se avental de mangas compridas descartável com gramatura minima de $40 \mathrm{~g} / \mathrm{m}^{2}$ para proporcionar uma barreira de impermeabilidade (IZZETTI $R$, et al., 2020; DE CAMPOS TUÑAS IT, et al., 2020; XU X, et al., 2020). 
Os aerossóis gerados nos procedimentos odontológicos medem cerca de $50 \mu \mathrm{m}$. As máscaras cirúrgicas regulares usadas em odontologia (quando usadas corretamente e trocadas com frequência) oferecem cerca de $80 \%$ de taxa de filtração desses aerossóis. Essa é uma boa proteção para a odontologia eletiva em circunstâncias normais, sabendo que a maioria de nossos pacientes está saudável (COULTHARD P, 2020).

A grande preocupação é que o vírus transmissor da COVID-19 mede em torno de $120 \mathrm{~nm}(0,12 \mu \mathrm{m})$ e os tamanhos de partículas em aerossol variam de 3 a $100 \mathrm{~nm}$, não sendo filtrados por mascaras convencionais. O uso de um respirador FFP3 oferece uma taxa de filtração de 99\% de todas as partículas medindo até 0,6 $\mu \mathrm{m}$. Sendo assim, a OMS recomenda o uso de um respirador de partículas pelo menos tão protetor quanto um N95 certificado pelo Instituto Nacional dos EUA de Segurança e Saúde no Trabalho (NIOSH), padrão FFP2 da União Europeia (UE), ou equivalente, ao executar procedimentos de geração de aerossóis. Estas também devem ser empregadas nos casos de atendimentos de urgência (COULTHARD P, 2020).

No caso apresentado, o cirurgião-dentista se paramentou de acordo com as instruções da OMS, a fim de evitar qualquer tipo de infecção, incluindo faceshild, óculos, a máscara utilizada pelo professional foi a PFF2, pois é capaz de filtrar em ate $96 \%$ o vírus da COVID-19 (MENG L, et al., 2020). A OMS recomenda que o público em geral não use máscaras médicas, pois isso pode causar custos desnecessários e sobrecarga de compras, sendo indicada nesses casos a máscara de tecido com tripla camada (COULTHARD P, 2020).

\section{CONSIDERAÇÕES FINAIS}

Diante do agravamento do caso da pandemia de COVID-19 no contexto atual, cabe ao cirurgião-dentista cautela e restrição da execução de procedimentos odontológicos apenas em caráter de urgências e emergências, considerando o potencial de contaminação característico do vírus, a possibilidade de contágio causado pela saliva e o risco de disseminação de aerossol no consultório, produzidos principalmente pelos materiais odontológicos mais utilizados nesses ambientes. Além disso, existe ainda a necessidade de estudos clínicos randomizados e controlados para que haja uma padronização dos atendimentos clínicos a serem realizados.

\section{REFERÊNCIAS}

1. ASSOCIAÇÃO DENTAL AMERICANA. Orientações sobre atendimento odontológico de emergência e não emergenciais, 2020.

2. BRASIL. Ministério da Saúde. Serviços odontológicos: prevenção e controle de riscos, 2006.

3. COULTHARD P. Dentistry and coronavirus (COVID-19)-moral decision-making. British Dental Journal, 2020; 228(7), 503-505.

4. CONSELHO REGIONAL DE ODONTOLOGIA DE SERGIPE, Manejo odontológico ambulatorial em tempos de covid19. Decisão № 08/2020, 2020.

5. DE CAMPOS TUÑAS IT, et al. Doença pelo Coronavírus 2019 (COVID-19): Uma abordagem preventiva para Odontologia. Revista Brasileira de Odontologia, 2020; 77, 1-7.

6. DEL RIO C, et al. COVID-19—new insights on a rapidly changing epidemic. Jama, 2020; 323(14): 1339-1340

7. DOS ANJOS LM, et al. Riscos de infecção cruzada frente a pandemia do COVID-19 em âmbito odontológico: o que há de mais recente na literatura?. Revista Eletrônica Acervo Saúde, 2020;12(9).

8. FRANCO AG, et al. Preferência dos cirurgiões-dentistas por atendimentos de urgência e emergência frente ao Covid19. InterAmerican Journal of Medicine and Health, 2020; 3.

9. FRANCO JB, et al. Utilização de protetores bucais em pacientes internados na unidade de terapia intensiva: proposta de protocolo. Arq Med Hosp Fac Cienc Med Santa Casa São Paulo. 2015; 60: 85-90.

10. GIACOMELLI A, et al. Self-reported olfactory and taste disorders in SARS-CoV-2 patients: a crosssectional study. Clin Infect Dis. 2020.

11. GUAN WJ, et al. Clinical characteristics of 2019 novel coronavirus infection in China. MedRxiv, 2020.

12. IYER P, et al. Impact of COVID-19 on dental education in the United States. Journal of Dental Education, 2020.

13. IZZETTI R, et al. COVID-19 transmission in dental practice: brief review of preventive measures in Italy. Journal of dental research: 2020.

14. LARSON EL, et al. An organizational climate intervention associated with increased handwashing and decreased nosocomial infections. Behav Med. 2000; 26(1):14-22.

15. LU CW, et al. A transmissão 2019-nCoV através da superfície ocular não deve ser ignorada. The Lancet, 2020.

16. MAHASE E. Coronavirus: covid-19 has killed more people than SARS and MERS combined, despite lower case fatality rate., 2020. 
17. MARTINS-FILHO PR, et al. Recommendations for a safety dental care management during SARS-CoV-2 pandemic. Revista Panamericana de Salud Pública, 2020; 44, 51.

18. MENG L, et al. Coronavirus Disease 2019 (COVID-19): Emerging and Future Challenges for Dental and Oral Medicine. J Dent Res., 2020.

19. ORGANIZAÇÃO MUNDIAL DA SAÚDE. Orientação sobre o uso de máscaras na comunidade, durante o atendimento domiciliar e em serviços de saúde no contexto do novo surto de coronavírus (covid-19). 2020.

20. PHELAN AL, et al. The novel coronavirus originating in Wuhan, China: challenges for global health governance. Jama, 2020; 323(8), 709-710.

21. PENG X, et al. Transmission routes of 2019-nCoV and controls in dental practice. Int J Oral Sci. 2020;12(1):9. 10.

22. VAN DOREMALEN N, et al. Aerosol and surface stability of SARS-CoV-2 as compared with SARS-CoV-1. New England Journal of Medicine, 2020; 382(16), 1564-1567.

23. WANG D, et al. Clinical characteristics of 138 hospitalized patients with 2019 novel coronavirus-infected pneumonia in Wuhan, China. Jama, 2020; 323(11), 1061-1069.

24. XU X, et al. Saliva potential diagnostic value and transmission of 2019-nCoV. International Journal of Oral Science, 2020; 12(1): 1-6.

25. YOON JG, et al. Clinical Significance of a High SARS-CoV-2 Viral Load in the Saliva. Journal of Korean medical science, 2020; 35(20). 